\title{
Atypical Cutaneous Cytomegalovirus (CMV) Infections in Non-AIDS Patients; a Report of 2 Cases
}

\author{
Chutika Srisuttiyakorn*, Puangjai Varapornpipat, Kobkul Aunhachoke \\ Division of Dermatology, Department of Medicine, Phramongkutklao Hospital, Bangkok, Thailand
}

Received: November 21, 2016; Accepted: December 28, 2016; Published: January 06, 2017

*Corresponding author: Chutika Srisuttiyakorn, Division of Dermatology, Department of Medicine, Phramongkutklao Hospital, Bangkok, Thailand. E-mail: schuti101@gmail.com

\begin{abstract}
Cytomegalovirus (CMV) is a DNA virus belonging to the herpes virus group. The infection from this virus is increasing in the immune compromised patients, especially AIDS or organ transplant recipients. Nevertheless, the skin lesion is uncommon. We present two cases of atypical cutaneous CMV infection.

The first case was a 66 year-old Thai woman with overlapping syndrome, on treatment with multiple immune suppressants. She presented with high grade fever and asymptomatic purpuric papules and pustules on her forearms and legs. Laboratory investigations showed bicytopenia from complete blood count. Chest radiography and high-resolution computed tomography of the chest revealed lung nodules.
\end{abstract}

The second case was a 49-year-old Thai woman with Systemic Lupus Erythematosus (SLE) and obtained multiple immune suppressants. She presented with fever and multiple erythematous papules with ulcers of the extremities and trunk. Basic laboratory investigations were normal.

The skin biopsies from both cases showed perivascular infiltration with inflammatory cells and numerous large round eosinophilic intranuclear inclusion bodies (owl's eye appearance) in the dermis. The CMV antigen stained the cytoplasm of owl's eye cells.

Further investigations presented high level CMV viral load in both cases. The diagnosis CMV infection was made.

In conclusion, we presented the cases with cutaneous CMV infection in immune compromised host. This group of patients is susceptible to variety of infections and presented with atypical manifestations. Cutaneous manifestations with skin biopsy in some cases may play a major role for the correct diagnosis and prompt treatment.

Keywords: Cytomegalovirus; Systemic lupus Erythematosus; Rheumatoid Arthritis; Anti-Phospholipid Syndrome;

\section{Abbreviation}

Atypical cutaneous lesions in CMV infection

\section{Introduction}

Cytomegalovirus (CMV) is a DNA virus belonging to the herpesviridae family. It is a common opportunistic infection in fetus, allograft and bone marrow transplant recipients and AIDS
[1]. The infection was detected close to $100 \%$ in developing countries $[1,2]$. The transmission occurs via body fluids (saliva, urine, blood, semen, vaginal secretion, breast milk) and also via transplant organs [2]. In the primary infection, CMV can infect many cell types and causes viremia, using blood leukocytes as transport medium [2, 3]. After the primary infection, CMV stayed latently lifelong in the hosts and rarely causes diseases in immunocompetent individuals [3].

\section{Case reports}

\section{Case 1}

A 66-year-old woman presented with high grade fever and fatigue for 1 month. Three weeks after the presence of fever, she developed asymptomatic skin rashes on the extremities. Her underlying disease was overlapped syndrome (rheumatoid arthritis with anti-phospholipid syndrome). Her conditions were controlled with methotrexate $15 \mathrm{mg} / \mathrm{wk}$, hydroxychloroquine $200 \mathrm{mg} / \mathrm{d}$, prednisolone $10 \mathrm{mg} / \mathrm{d}$, leflunomide $20 \mathrm{mg} / \mathrm{d}$, azathioprine $50 \mathrm{mg} / \mathrm{d}$, rituximab $1000 \mathrm{mg} / \mathrm{mo}$ (total 2 dose), aspirin $81 \mathrm{mg} / \mathrm{d}$ and enalapril $40 \mathrm{mg} / \mathrm{d}$.

Physical examination revealed $38.7^{\circ} \mathrm{C}$ body temperature. There were multiple ill-defined erythematous purpuric patches and pustules on the forearms and legs (Figure 1). Other examinations were unremarkable.

The skin biopsy from the skin lesion on the forearm showed superficial and deep perivascular and interstitial infiltrations composed of predominantly neutrophils, nuclear dusts and extravasated red blood cells. There were vascular walls destruction and fibrinoid depositions. Large cells with eosinophilic intracytoplasmic and intranuclear inclusion bodies (owl's eye cells) were observed in the vascular endothelium (Figure 2). The immunohistochemistry for CMV antigen highlighted in the cytoplasm of these owl's eye cells (Figure 3).

Further laboratory investigations revealed anemia, lymphopenia and high CMV viral load (2,418,532 copies/ml). Chest x-ray showed reticulonodular infiltration in both lungs. The retinal examination from an opthalmologist was normal.

She was diagnosed as active CMV infection. The treatment 


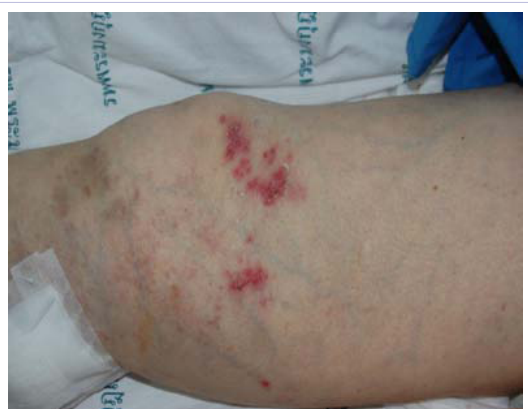

Figure 1: Clinical appearances of Case 1 presenting as purpuric patches and pustules on right thigh.

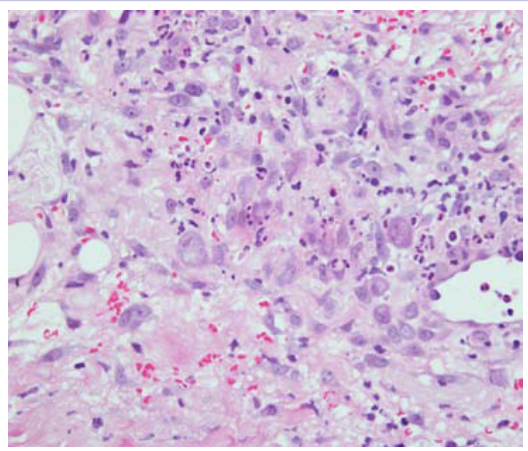

Figure 2: The section demonstrated large cells with eosinophilic intracytoplasmic and intranuclear inclusion bodies (owl's eye cells) observed in the vascular endothelium in the dermis (H\&E, $\mathrm{x} 400)$.

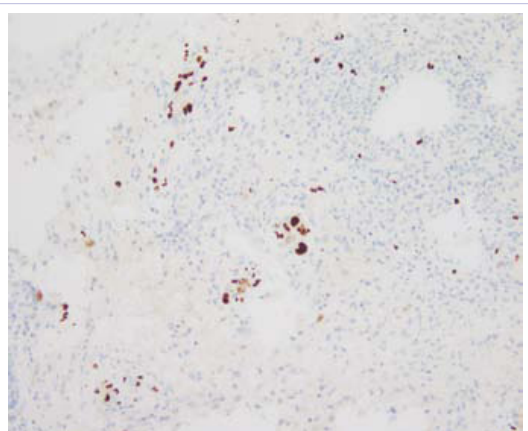

Figure 3: The immunohistochemistry for CMV antigen highlighted in the cytoplasm of these owl's eye cells.

was started with intravenous ganciclovir. After 1 week of the treatment, her condition turned worse. She still had high grade fever. Acid fast bacilli were found from the sputum examination which was compatible with pulmonary tuberculosis. She developed dyspnea and passed away from respiratory failure before starting the anti-tuberculous agents.. -

\section{Case 2}

A 49-year-old woman presented with high grade fever and asymptomatic skin rashes for 3 weeks. She had underlying diseases as systemic lupus erythematosus (SLE) which was well controlled with mycophenolate mofetil $2 \mathrm{~g} / \mathrm{d}$, prednisolone 40 $\mathrm{mg} / \mathrm{d}$ and chloroquine $250 \mathrm{mg} / \mathrm{d}$.
Physical examinations showed $38.8^{\circ} \mathrm{C}$ body temperature. There were multiple well-defined erythematous crusted papules on her right arm, right forearm and abdominal wall with a solitary ill-defined erythematous papule with shallow ulcer and pustules on the right elbow (Figure 4,5). Other examinations were unremarkable.

The skin biopsy form the ulcer revealed dense superficial and deep perivascular and interstitial infiltration composed of lymphocytes and histiocytes. There were vascular wall destruction with fibrinoid deposition and numerous large round cells with eosinophilic intranuclear inclusion bodies (owl's eye cells) in the endothelial cells (Figure 6). The immunohistochemistry for CMV antigen highlighted in the cytoplasm of owl's eye cells (Figure 7).

Further laboratory investigations showed anemia, lymphopenia and also high CMV viral load (2,624,532 copies/ $\mathrm{ml}$ ). The retinal examination from an opthalmologist was normal.

She was diagnosed as active CMV infection. The treatment was started with intravenous ganciclovir. After 8 weeks of the treatment, the lesions were resolved without any complication.

\section{Discussion}

CMV infection causes various dermatologic and systemic disorders but usually asymptomatic in immunocompetent hosts [3]. The most common clinical presentation is a mononucleosislike syndrome resemble to EBV infection [2, 4].

In immunocompromised host, CMV infection presents as a wide variety of manifestations depending on the degree of immunosuppression which is a major cause of morbidity and mortality.. This group of patients usually acquires disseminated CMV disease involving many organs, resulting to chorioretinitis, pneumonitis, gastrointestinal, Central Nervous System (CNS), renal, bone marrow and endocrine abnormalities $[2,5]$.

Nevertheless cutaneous involvement of CMV is a rare manifestation [5]. Genital ulcers are the most common skin lesions among the AIDS and non-AIDS, immunocompromised patients and usually accompany with polymicrobial infection, especially herpes simplex virus infection [6, 7]. Morbiliform eruptions, purpura, vesiculobullous lesions, nodules, papular eruptions, verrucous lesions and ulcers were also reported $[2,6]$.

The typical histopathology of tissues infected with cytomegalovirus shows characteristic cells with intranuclear and intracytoplasmic inclusion bodies (owl's eye appearance) which was only limited to fully developed lesions $[6,8]$. In early infection, the initial cellular change is cell enlargement with enlarged basophilic nucleus and prominent nucleolus. Then the cell continues to enlarge and the cytoplasm has smudged, amphophilic, bubbly quality. The fully developed change shows basophilic intranuclear and intracytoplasmic inclusion bodies. While the CMV infection resolves, the cell including the nucleus shrinks $[6,8]$. The affected cells are mostly mesenchymal cells, especially endothelial cells. Fibroblasts, inflammatory cells, and rarely epithelial cells are less commonly affected $[6,8,9]$.

Additional histopathologic features include leukocytoclastic 


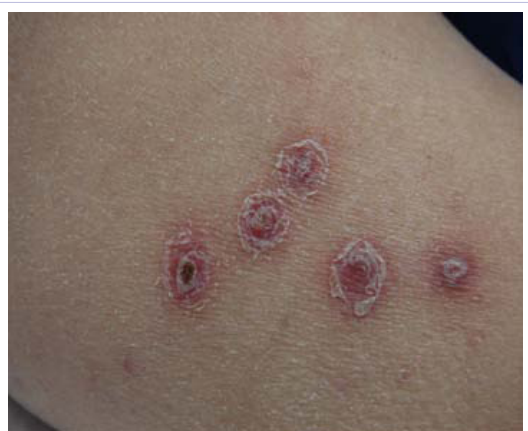

Figure 4: Clinical appearance of Case 2 presenting as crusted erythematous papules and ulcerated papules on arms and elbow

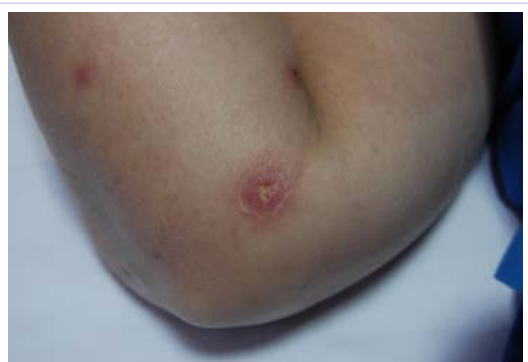

Figure 5: Clinical appearance of Case 2 presenting as crusted erythematous papules and ulcerated papules on arms and elbow.

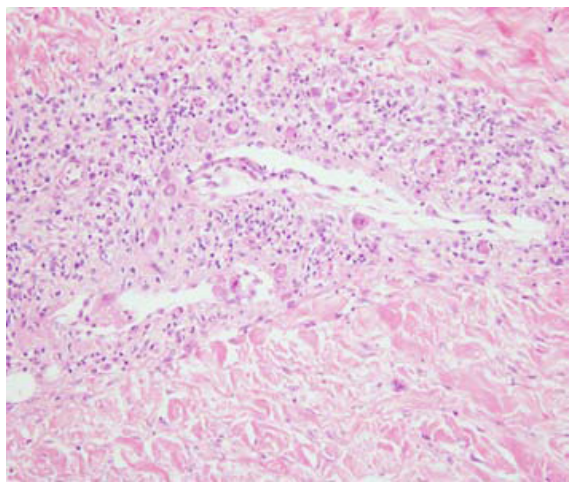

Figure 6: The section demonstrated large cells with eosinophilic intracytoplasmic and intranuclear inclusion bodies (owl's eye cells) observed in the vascular endothelium in the dermis (H\&E, x400).

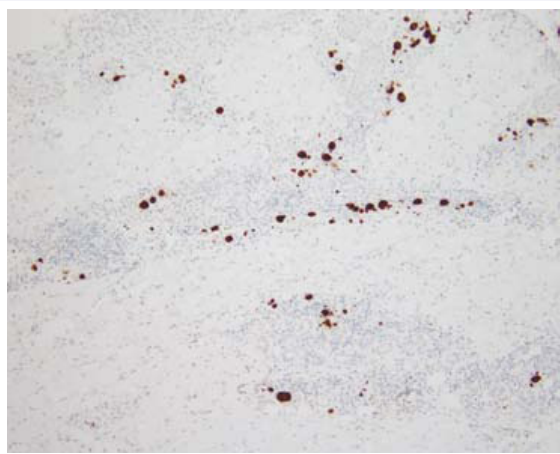

Figure 7: The immunohistochemistry for CMV antigen highlighted in the cytoplasm of these owl's eye cells. vasculitis, eccrine squamous syringometaplasia, and neuritis [10-12]. The diagnosis of CMV vasculitis is made when there are evidence of vascular destruction (vessel wall damage, necrosis and luminal obstruction). CMV associated-vasculitis can occur in the internal organs, especially GI tract and central nervous system [13]. The vascular injury can be caused by either direct endothelial damage by virus, which usually shows the typical inclusion bodies in the endothelial cells or via induction of immune-mediated hypersensitivity [10, 13, 14]. Furthermore, cytomegalovirus neuritis was diagnosed by demonstrate the CMV inclusion bodies in the Schwann cells [12].

In addition to CMV infection in AIDs and transplant recipients, there were many reports of the association of CMV infection and connective tissue diseases.

In SLE, the increased risk of infections due to the prolonged use of immunosuppressants was mentioned. Ramos-Casals M, et al, showed that CMV was the most common viral infection in SLE [15]. CMV antibodies were detected in nearly 50\% of SLE cases who presented with acute viral infection and the majority of the cases were Asian. [15]

The association of CMV infection and SLE is still unclear but may involve many factors. Active SLE induces immune reactivation which induces proliferation of immune cells, resulting in proliferation of latent CMV in the cells. In addition, immunosuppressive treatments may also allow the reactivation of latent virus [16-18]. In the contrary, CMV infection can also trigger the development and the flare of SLE $[16,17]$. This group of patients presented with acute CMV infection and positive IgM anti CMV antibodies prior to the diagnosis of SLE [16-19]. The mechanism of CMV induced autoimmunity had not been fully clarified. The possible mechanism is the cross-reactivity between T-cell and CMV antigens in susceptible individual. [19-20]

CMV has been reported as a triggering factor of vascular damage in systemic sclerosis. ${ }^{21}$ Moreover, CMV DNA specific antigens were detected in synovial tissue and fluid from rheumatoid arthritis joints in $10-50 \%$ of the patients, but the role of involving the disease is still unclear. [21-25]

The clinical manifestations of active CMV infection can also mimic the active SLE flare as seen in our cases with the presenting symptoms of fever, skin lesions resemble cutaneous vasculitis, lymphopenia and anemia [18]. The diagnosis of CMV infection was confirmed by the feature of CMV vasculitis in the skin biopsies and the elevated serum CMV viral load. The causative factors of CMV infection in our cases may be from prolonged immunosuppressants reactivated the latent CMV infection.

The first line treatment for CMV infection is intravenous ganciclovir, while oral valganciclovir is preferred for prophylaxis and preemptive therapy [26-28]. The second-line treatment is foscarnet which is limited to be used in ganciclovir-resistant CMV infection or in patients contraindicated to use ganciclovir. The third agent is cidoforvir which is limited to be used due to the presence of poor bioavailability and nephrotoxicity. [26] 
In conclusion, we reported two cases of active CMV infections who presented with non-specific skin lesions. Both cases had underlying connective tissue diseases, controlled with multiple immunosuppressants. The clinical presentation of CMV infection can mimic flare of the underlying diseases. The careful physical examinations and proper investigations are keys for the diagnosis and prompt management.

\section{References}

1. Griffiths P, Baraniak I, Reeves M. The pathogenesis of human cytomegalovirus. J Pathol. 2015;235(2):288-297. doi: 10.1002/ path.4437.

2. Mendoza N, Madkan V, Sra K, et al. Human Herpesviridae. In: Bolognia JL, Jorizzo JL, Schaffer JV, editors. Dermatology. 3rd ed. New York: Elsevier; 2012; p.1336-1338.

3. Varani S, Landini MP. Cytomegalovirus-induced immunopathology and its clinical consequences. Herpesviridae. 2011;2(1):6 doi: $10.1186 / 2042-4280-2-6$

4. Tsai YJ, Yu HR, Hsu TL, Chuan MT, Chieh-Jen Wu. Cutaneous cytomegalovirus infection in a patient with T-cell lymphoma, a case report and literature review. Dermatol Sinica. 2000;18:127-135.

5. Prasad N, Jain M, Gupta A, Sharma RK, Vinita Agarwal. An unusual case of CMV cutaneous ulcers in a renal transplant recipient and review of literature. NDT Plus. 2010;3(4):379-382. doi: 10.1093/ndtplus/ sfq082

6. Choi YL, Kim JA, Jang KT, Kim DS, Kim WS, Lee JH, et al. Characteristics of cutaneous cytomegalovirus infection in non-acquired immune deficiency syndrome, immunocompromised patients. Br J Dermatol. 2006;155(5):977-982.

7. Dauden E, Fernandez-Buezo G, Fraga J, Cardenoso L, García-Díez A. Mucocutaneous presence of cytomegalovirus associated with human immunodeficiency virus infection: discussion regarding its pathogenetic role. Arch Dermatol. 2001;137:443-448.

8. Resnik KS, DiLenardo M, Millet M. Histopathologic findings in cutaneous cytomegalovirus infection. Am J Dermatopathol 2000;22(5):397-407

9. García-Patos V, Pujol RM, Curell R, de Moragas JM. Cytomegalovirusinduced cytopathic changes in skin biopsy specimens: clinicopathologic study in patients with the acquired immunodeficiency syndrome and an active extracutaneous cytomegalovirus infection. Arch Dermatol 1992;128(11):1552-1553.

10. Chetty R, Bramdev A, Govender D. Cytomegalovirus-induced syringosquamous metaplasia. Am J Dermatopathol. 1999;21(5):487490

11. Baysse L, Boralevi F, Lepreux S, Boyer A, Morel C, Léauté-Labrèze C, et al. Eccrine squamous syringometaplasia and cytomegalovirus infection. Rev Med Interne. 2003;24(6):394-398.

12. Ramdial PK, Dlova NC, Sydney C. Cytomegalovirus neuritis in perineal ulcers. J Cutan Pathol. 2002;29(7):439-444.

13. Golden MP, Hammer SM, Wanke CA, Albrecht MA. Cytomegalovirus vasculitis. Case reports and review of the literature. Medicine. 1994;73(5):246-255.
14.Arslan F, Batirel A, Mert A, Ozer S. Cytomegalovirus (CMV) related cutaneous necrotizing vasculitis: case report and literature review. Braz J Infect Dis. 2012;16(5):482-485. doi: 10.1016/j. bjid.2012.08.002.

15. Ramos-Casals M, Cuadrado MJ, Alba P, Sanna G, Brito-Zerón $\mathrm{P}$, Bertolaccini L, et al. Acute viral infections in patients with systemic lupus erythematosus. Medicine. 2008;87(6):311-318.

16. Yamazaki S, Endo A, Iso T, Abe S, You Aoyagi, Mitsuyoshi Suzuki, et al. Cytomegalovirus as a potential trigger for systemic lupus erythematosus: a case report. BMC Res Notes. 2015;28(8):487. doi: 10.1186/s13104-015-1520-2

17. Rozenblyum EV, Levy DM, Allen U, Harvey E, Hebert D, Silverman ED. Cytomegalovirus in pediatric systemic lupus erythematosus: prevalence and clinical manifestations. Lupus. 2015;24(7):730735. doi: $10.1177 / 0961203314565443$

18. Zhang J, Dou Y, Zhong Z, Su J, Xu D, Tang F, et al. Clinical characteristics and therapy exploration of active human cytomegalovirus infection in 105 lupus patients. Lupus. 2014;23(9):889-897. doi: $10.1177 / 0961203314532560$

19. Pérez-Mercado AE, Vilá-Pérez S. Cytomegalovirus as a trigger for systemic lupus erythematosus. J Clin Rheumatol. 2010;16(7):335337. doi: 10.1097/RHU.0b013e3181f4cf52.

20. Hiemstra H, Schloot N, Van Veelen P, Willemen SJ, Franken KL, van Rood JJ, et al. Cytomegalovirus in autoimmunity: T cell crossreactivity to viral antigen and autoantigen glutamic acid decarboxylase. Proc Natl Acad Sci USA. 2001;98(7):3988-3991.

21.Varani S, Landini MP. Cytomegalovirus-induced immunopathology and its clinical consequences. Herpesviridae. 2011;2(1):6. doi: 10.1186/2042-4280-2-6

22. Einsele H, Steidle M, Muller CA, Fritz P, Zacher J, Schmidt $H$, et al. Demonstration of cytomegalovirus (CMV) DNA and anti-CMV response in the synovial membrane and serum of patients with rheumatoid arthritis. J Rheumatol. 1992;19(5):677-681.

23. Hamerman D, Gresser I, Smith C. Isolation of cytomegalovirus from synovial cells of a patient with rheumatoid arthritis. J Rheumatol. 1982;9(5):658-664.

24. Mehraein Y, Lennerz C, Ehlhardt S, Remberger K, Ojak A, Zang KD. Latent Epstein-Barr virus (EBV) infection and cytomegalovirus (CMV) infection in synovial tissue of autoimmune chronic arthritis determined by RNA- and DNA-in situ hybridization. Mod Pathol. 2004;17(7):781-789.

25. Murayama T, Jisaki F, Ayata M, Sakamuro D, Hironaka T, Hirai K, et al. Cytomegalovirus genomes demonstrated by polymerase chain reaction in synovial fluid from rheumatoid arthritis patients. Clin Exp Rheumatol. 1992;10(2):161-164

26. Torres-Madriz G, Boucher HW. Immunocompromised hosts: perspectives in the treatment and prophylaxis of cytomegalovirus disease in solid-organ transplant recipients. Clin Infect Dis. 2008;47(5):702-711.

27. Kimberlin DW. Antiviral therapy for cytomegalovirus infections in pediatric patients. Semin Pediatr Infect Dis. 2002;13(1):22-30.

28. Tan BH. Cytomegalovirus Treatment. Curr Treat Options Infect Dis. 2014;6(3):256-270 